\title{
STATIN USE IN BRAZIL: FINDINGS AND IMPLICATIONS
}

do Nascimento RCRM ${ }^{1,2}$, Guerra Jnr AA ${ }^{2,3}$, Alvares J2,3, Gomes $\mathrm{IC}^{4}$, *Godman B5,6,7, Bennie $\mathrm{M}^{5}$, Kurdi $\mathrm{AB}^{5}$, Acurcio $\mathrm{F}$ de $\mathrm{A}^{2,3}$

${ }^{1}$ Post-graduated program of Medicines and Pharmaceutical Assistance, School of Pharmacy. Federal University of Minas Gerais (UFMG). Belo Horizonte, Minas Gerais, Brazil

${ }^{2}$ SUS Collaborating Centre for Technology Assessment and Excellence in Health (CCATES),

School of Pharmacy, Federal University of Minas Gerais, Brazil. Email: recmacedo@gmail.com; augustoguerramg@gmail.com; jualvares@gmail.com; fracurcio@gmail.com

${ }^{3}$ Department of Social Pharmacy. School of Pharmacy. Federal University of Minas Gerais

(UFMG). Belo Horizonte, Minas Gerais, Brazil

${ }^{4}$ Faculdade de Ciências Médicas. Belo Horizonte, Minas Gerais, Brazil. Email:

icgomes04@yahoo.com.br

${ }^{5}$ Strathclyde Institute of Pharmacy and Biomedical Sciences, University of Strathclyde, Glasgow,

UK. Email: Brian.Godman@strath.ac.uk; marion.bennie@strath.ac.uk;

amanj.baker@strath.ac.uk

Division of Clinical Pharmacology, Karolinska Institutet, Stockholm, Sweden. Email:

Brian.Godman@ki.se

${ }^{7}$ Health Economics Centre, Liverpool University Management School, Liverpool, UK. Email:

Brian.Godman@liverpool.ac.uk

*Author for correspondence: Brian Godman, Strathclyde Institute of Pharmacy and Biomedical Sciences, University of Strathclyde, Glasgow G4 ORE, United Kingdom. Email: brian.godman@strath.ac.uk. Telephone: 0141548 3825. Fax: 01415522562 and Division of Clinical Pharmacology, Karolinska Institute, Karolinska University Hospital Huddinge, SE-141 86, Stockholm, Sweden. Email: Brian.Godman@ki.se. Telephone + 46858581068 . Fax + 468 59581070

(Accepted for publication Current Medical Research and Opinion - please keep CONFIDENTIAL)

\section{ABSTRACT}

Introduction and objectives: Stains have become an integral part of treatment to reduce cardiac events in patients with cardiovascular disease. However, their use within the public healthcare system in Brazil is unknown. Consequently, we sought to determine and characterize statin use in primary healthcare delivered by the public health system (SUS) in Brazil and evaluate associated patient factors to improve future use. Methods: Cross-sectional study with a national representative sample from five Brazilian regions, derived from the National Survey on Access, Use and Promotion of Rational Use of Medicines using a multi-stage complex sampling plan. Patients over 18 years old were interviewed from July/2014 to May/2015. Prevalence of statin use and statins' self-reported adherence were determined amongst medicine users. The association between statin use and sociodemographic/health condition variables were assessed using logistic regression. Results: 8,803 patients were interviewed; of which, 6,511 were medicines users. The prevalence of statins use was $9.4 \%$ with simvastatin $(90.3 \%)$, atorvastatin $(4.7 \%)$ and rosuvastatin $(1.9 \%)$ the most used statins. Poor adherence was described by $6.5 \%$ of patients. Statins use was significantly associated with age $\geq 65$ years old, higher educational level, residence in the South, metabolic and heart diseases, alcohol consumption and polypharmacy. Conclusions: This is the first population based study in Brazil to assess statin use in SUS primary healthcare patients. Addressing inequalities in access and use of medicines including statins is an important step in achieving the full benefit of statins in Brazil, with the findings guiding future research and policies.

KEYWORDS: Cardiovascular Diseases; Hypercholesterolemia; Statins; Pharmaceutical Services; Primary Health Care; Drug Utilization, Brazil 


\section{Introduction}

Chronic, non-communicable diseases (NCDs) are one of the major health and development challenges of the 21 st century with appreciable burden across countries [1,2]. The burden of NCDs is predicted to increase with the ageing populations, urbanisation, and globalisation of risk factors [3-5]. Cardiovascular diseases (CVD) are the leading cause of NCD deaths worldwide, with the total annual number of NCD deaths projected to increase to 52 million by $2030[5]$.

In view of the rising prevalence of NCDs, and their impact on morbidity and mortality, the Pan American Health Organization (PAHO) drew up a Plan of Action for 2013 to 2019. The objective is to prevent and control NCDs in view of their growing burden [6], which is in line with the Sustainable Development Goal for NCDs proposed by the World Health Organisation (WHO) $[5,7]$ Universal health coverage, including access to essential medicines, people-centred primary health care and social protection mechanisms are important tools to support prevention and control of NCDs [8,9]. Patient co-payment is a particular issue affecting adherence to medicines negatively impacting on morbidity and mortality [10-12].

The constitutional right to health is guaranteed in Brazil and the implementation of the Sistema Único de Saúde (SUS), and universal coverage health system, has enabled greater access to health care [13]. CVD is the main cause of hospital admissions and death in Brazil [14-16], Medicines, including statins, are the cornerstone of CVD prevention and treatment [6, 17-20]. Special attention is paid to atherosclerotic the Brazilian Guidelines for the prevention of $\mathrm{CV}$ events, with the treatment of dyslipidemia comprises two major approaches: nonpharmacological and pharmacological therapy [21,22]. Overall CVD prevention is a cost effective strategy in many scenarios, including population-based approaches and actions directed at high-risk individuals $[19,21]$. Socioeconomic status is an additional factor contributing to CVD risk [19]. Half of the CVD deaths, before the age of 65 , can be attributed to poverty, social inequalities and educational level [14]. Inadequate diet, low physical activity, alcohol consumption and smoking are also more prevalent in the poorer social classes of the population $[23,24]$.

Statins are the most commonly used lipid lowering medicines in clinical practice today due to the scientific evidence regarding their efficacy and relative safety [17, 19-21,25]. Whilst there may be differences between the statins, it is unclear whether these differences impact on clinical outcomes in routine clinical practice and whether one statin should be preferred over another $[25,26]$. This changes when there are appreciable cost differences as seen when generic simvastatin became available [27-30]. Within the Brazilian healthcare system, statins became available in 2002 , and currently there are five statins provided by SUS: atorvastatin, fluvastatin, lovastatin, pravastatin and simvastatin (Figure 1). 
Figure 1. Use of statins for the prevention of cardiovascular events according to the Brazilian Guideline (Adapted from Brazil, 2013)

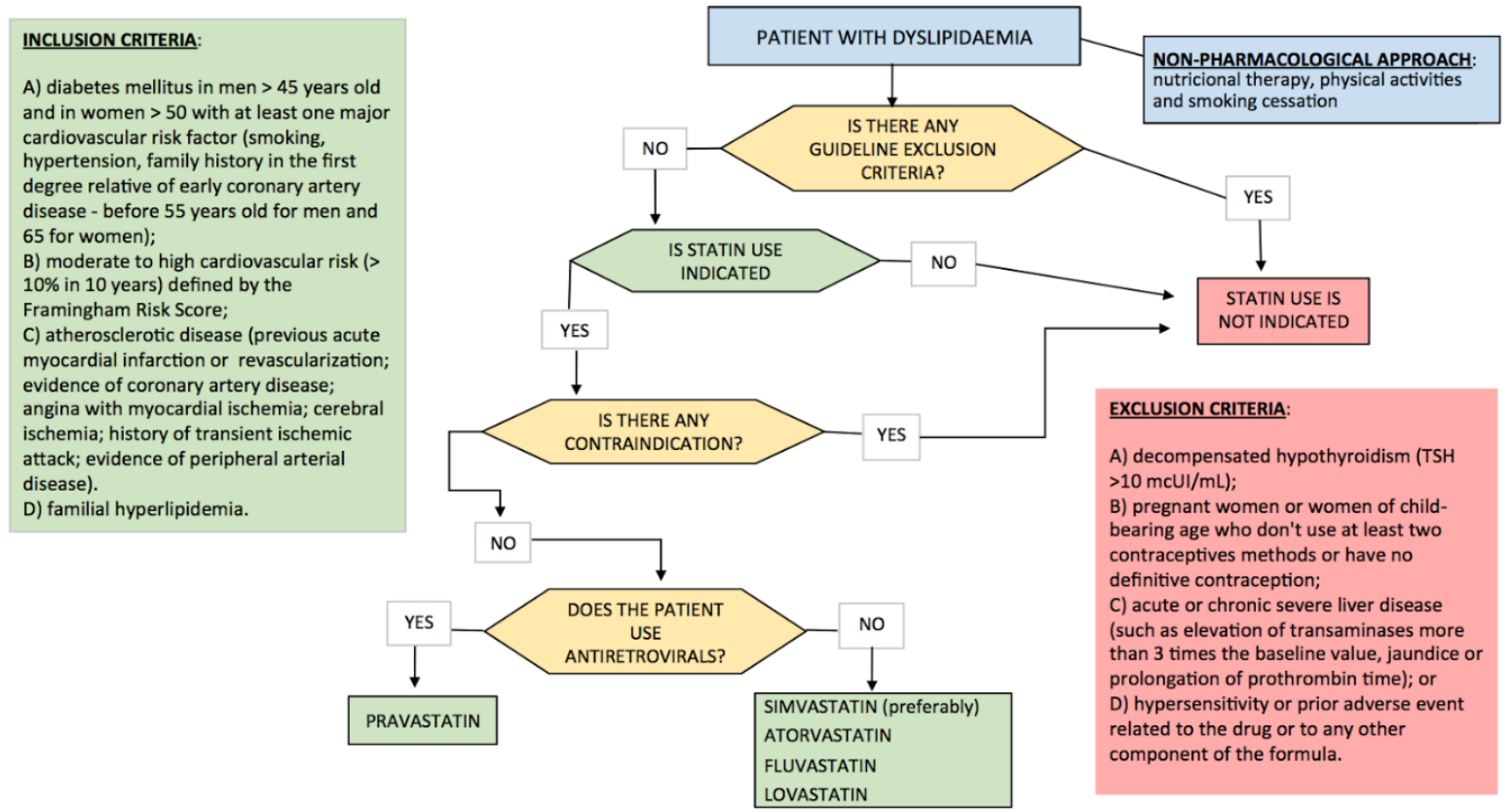

Simvastatin is the only statin included in the Basic Component of Pharmaceutical Services provided via primary health care services. To access simvastatin the patient needs to present a GP's or a specialist's prescription at SUS pharmacies, primary health care services or in private pharmacies accredited by the Popular Pharmacy Program ${ }^{1}$ (co-payment) [31]. The other statins (atorvastatin, fluvastatin, lovastatin and pravastatin) are provided through the Specialized Component of Pharmaceutical Assistance, funded by the federal and state governments [22]. However to access these statins without co-payment, pre-assessment is mandatory and patients need to present all the documents, examinations and forms established by the Brazilian guideline [22]. Whilst access to statins has been progressively facilitated with the inclusion of simvastatin through primary health care services and SUS pharmacies, there are concerns with their availability and usage [32].

Long-term adherence to statins is currently sub-optimal across countries [33,34], and needs to be addressed to reduce CVD morbidity and mortality [35-37]. Consequently, knowledge of medicines use in the real world is essential to develop pertinent health care strategies in high priority areas such as NCDs [38].

To appraise current access to, and rational use of. Medicines in primary healthcare settings, the first National Survey on Access, Use and Promotion of Rational Use of Medicines (PNAUMServices) was conducted in Brazil [39] from 2014 to 2015. As part of PNAUM - Services, this study aimed to quantify current statin use in SUS primary health care services and to characterise patient factors associated with their consumption. Based on a literature review [14, 40,41], we believe this is the first population based study in Brazil to assess the profile of statin use in primary healthcare service. The findings will guide future policies in Brazil to improve the management of patients with NCDs, including dyslipidemia.

\footnotetext{
${ }^{1}$ The Popular Pharmacy Program is a partnership between the Brazilian Ministry of Health and the private pharmaceutical retail sector. In addition to the free-of-charge medicines for hypertension, diabetes and asthma, under the "Saúde não tem preço" ("Health is priceless") strategy, the program provides statins for dyslipidemia with the Ministry of Health funding $90 \%$ of the medicine's price 34 -and the patient $10 \%$.
} 


\section{Methods}

The study data was extracted from the PNAUM-Services database. All the methodological procedures adopted in the planning and execution of the PNAUM-Services have been reported previously [39]. Briefly, the PNAUM was a cross-sectional, exploratory, and evaluative study, with a national representative sample from the five Brazilian regions, using a three multi-stage complex sampling plan including cities, primary health care services and patients (Figure 2). The sample sizes adopted in each region were: 60 cities, 300 health services and 1,800 patients.

Figure 2. Sampling plan of the Brazilian Survey on Access, Use and Promotion of Rational Use of Medicines - PNAUM Services, 2015

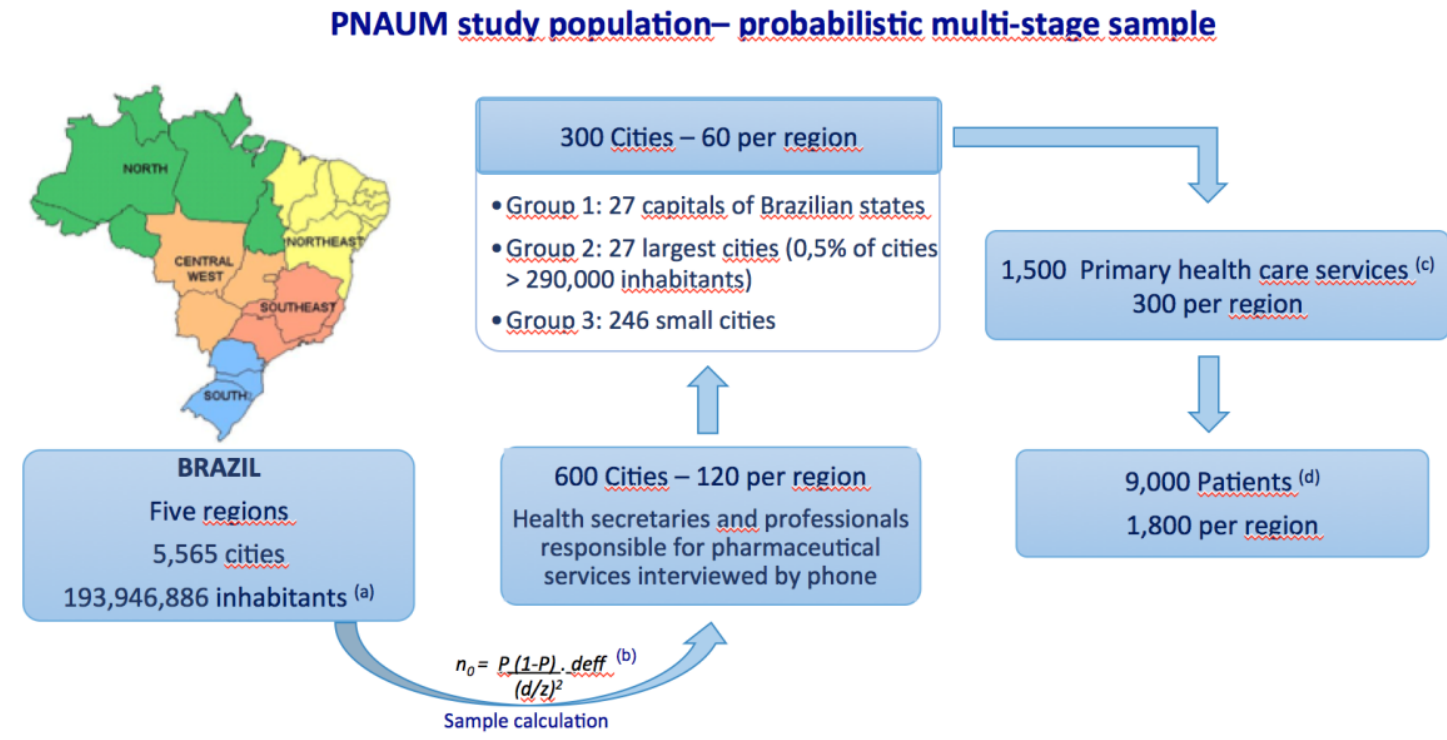

NB: (a) Population estimated for 2014 by the Brazilian Institute of Geography and Statistics (IBGE). (b) $P=0.50$ is the ratio of elements to be estimated as it leads to greater sample size; $z=1.96$ is the normal curve value reduced to the $95 \%$ level of confidence; deff is the design effect, and $d$ is the percentage sampling error. (c) Primary health care services were randomly selected from the National Registration of Health Establishments (CNES). (d) The average of GP appointments in the period spanned from July 2013 to May 2014 was adopted to estimate the number of patients to be interviewed in each service.

Patients over 18 years old were recruited and interviewed in primary health care services, from July 2014 to May 2015, using a specific structured questionnaire designed for the survey [39]. Personal information, including sociodemographic data (sex, age, ethnicity, marital status, educational level, economic class, region of country and private health insurance) and lifestyle characteristics (alcohol use, smoking, frequency of physical activity in the three previous months and diet) were collected from all respondents. The Brazilian criteria was adopted to classify the economic classes in five strata: A, B, C, D and E [41]. This is a measuring system that estimates the socioeconomic level of a household, based on several attributes and characteristics (consumer goods, monthly servants, education level, and public utility services such as piped water).

Regarding health conditions and use of medicines, patients were asked about what chronic diseases they have; any emergency care and hospitalization in the preceding 12 months; and any medicines' use in the 30 days prior to the interview date. To ensure greater accuracy, interviewers asked patients to present the prescriptions and/or packages of medicines they were currently taking, when available. Patients were further asked about how long they have been taking each medicine, how they accessed the medicines the last time they required them (free of charge, co-payment, private pharmacies or others) and if there was any difficulty in accessing their medicines. 
Patients who reported the use of at least one medicine were divided into two strata, statin users and non-statin users, according to whether they used statins or not. The medicines were classified in accordance with the fifth level of the Anatomical Therapeutic Chemical index (ATC) [42]. Polypharmacy was defined as the use of five or more medicines per patient, in line with other published studies [43-46]. Self-reported adherence to statins was assessed by asking patients whether they missed any dose in the seven days prior to the interview in accordance with previous studies [47-49]. Patients who reported missing at least one dose of a statin in the past seven days were classified as having poor adherence.

The association between statins use and sociodemographic variables (sex, age, marital status, educational level, economic class, having health insurance, residence region), lifestyle (alcohol consumption, smoking, physical activity), and indicators of health conditions (self-perception of health, number and main chronic diseases self-reported, emergency care and hospitalization) was assessed. Proportions were presented with respective $95 \%$ confidence intervals $(\mathrm{Cl})$, and numeric variables as mean \pm standard deviation.

For group comparison, the Pearson's Chi-square test with Rao-Scott correction was adopted, considering a significance level of $5.0 \%$. The association between statins use and co-variables was evaluated using logistic regression models. Univariate models were used to select variables to be included in the multivariate model, using a $p$-value $\leq 0.20$ as a cut-off point. The Backward method [50] was adopted to obtain the final model, which contained only those variables with a $p$-value $<0.05$. The adjustment quality was verified by the Hosmer-Lemeshow test. Data were analysed using the program $R \circledast$ version 3.2.1, with the survey package.

The survey was approved by the National Research Ethics Committee (CONEP), under Opinion $n^{\circ}$. 398,131/2013. All participants gave written informed consent for the interview, data collection and analysis.

\section{Results}

A total of 8,803 patients were interviewed in 1,305 primary health care services located in 272 Brazilian cities. Out of these, 6,511 patients $(76.2 \%)$ reported medicines use in the 30 days prior to the interview. The prevalence of statin use was $9.3 \%(n=603)$.

The majority of the statins users were female $(77.8 \%)$, between $45-64$ years old $(60.0 \%)$, of white skin colour $(53.6 \%)$, married $(68.2 \%)$, with incomplete elementary education $(48.7 \%)$, economic class C, with an estimated annual household income of R $\$ 25,980.00$ (U\$ 9,226.00) $(52.5 \%)$, lived in the South region $(37.5 \%)$, and did not have private health insurance $(87.6 \%)$ (Table 1). 
TABLE 1. Sociodemographic characteristics of statins users in the SUS primary health care. National Survey on Access, Use and Promotion of Rational Use of Medicines Services, 2015

\begin{tabular}{|c|c|c|c|c|c|}
\hline \multirow{3}{*}{ Variables } & \multicolumn{4}{|c|}{ Current statin users } & \multirow{3}{*}{ p-value } \\
\hline & \multicolumn{2}{|c|}{$\begin{array}{c}\text { Yes } \\
(n=603)\end{array}$} & \multicolumn{2}{|c|}{$\begin{array}{c}\text { No } \\
(n=5,908)\end{array}$} & \\
\hline & $\mathbf{n}^{\mathbf{a}}$ & $\%(95 \%$ CI $)$ & $\mathbf{n}^{\mathbf{a}}$ & $\%(95 \% \mathrm{CI})$ & \\
\hline Sex & & & & & 0.549 \\
\hline Female & 469 & $77.8(71.3-83.1)$ & 4,555 & $76.1(74.3-77.8)$ & \\
\hline Male & 134 & $22.2(16.9-28.7)$ & 1,917 & $23.9(22.2-25.7)$ & \\
\hline Age (years) & & & & & $<0.001$ \\
\hline $18-44$ & 54 & $9.6(6.5-14.0)$ & 2,817 & $45.6(43.0-48.3)$ & \\
\hline $45-64$ & 353 & $60.0(52.7-66.9)$ & 2,146 & $37.6(35.7-39.5)$ & \\
\hline$\geq 65$ & 196 & $30.4(25.3-36.0)$ & 891 & $16.8(14.9-18.8)$ & \\
\hline Skin color/ethnicity & & & & & $<0.001$ \\
\hline White & 308 & $53.6(45.5-61.5)$ & 2,146 & $40.9(37.2-44.6)$ & \\
\hline Brown & 253 & $41.0(33.6-48.9)$ & 3,163 & $49.8(45.9-53.7)$ & \\
\hline Black & 39 & $5.2(3.5-7.5)$ & 517 & $7.8(6.4-9.6)$ & \\
\hline Yellow & 1 & $0.2(0.0-1.7)$ & 46 & $1.3(0.6-2.9)$ & \\
\hline Indigenous & 0 & - & 22 & $0.3(0.1-0.6)$ & \\
\hline Marital status & & & & & $<0.001$ \\
\hline Single & 68 & $8.4(6.0-11.5)$ & 1,406 & $20.3(18.8-22.0)$ & \\
\hline Married/common-law marriage ${ }^{\mathrm{b}}$ & 376 & $68.2(62.5-73.4)$ & 3,640 & $65.1(63.1-67.2)$ & \\
\hline Others & 159 & $23.5(18.6-29.1)$ & 862 & $14.5(13.1-16.0)$ & \\
\hline Education level & & & & & $<0.001$ \\
\hline Illiterate & 95 & $16.3(11.2-23.3)$ & 553 & $10.7(8.7-13.1)$ & \\
\hline Incomplete elementary school & 265 & $48.7(41.7-55.7)$ & 2,245 & $42.5(39.1-46.0)$ & \\
\hline Elementary school & 80 & $12.0(9.0-15.8)$ & 755 & $12.7(10.6-15.0)$ & \\
\hline High school & 130 & $17.8(14.1-22.1)$ & 1,923 & $28.2(26.1-30.4)$ & \\
\hline$\geq$ Higher education & 33 & $5.2(3.5-7.6)$ & 432 & $6.0(5.1-7.0)$ & \\
\hline Economic class $^{\mathrm{c}}$ & & & & & 0.771 \\
\hline $\mathrm{A} / \mathrm{B}$ & 97 & $16.0(10.5-23.6)$ & 975 & $15.0(12.9-17.4)$ & \\
\hline $\mathrm{C}$ & 344 & $52.5(46.1-58.8)$ & 3,446 & $54.7(51.5-57.9)$ & \\
\hline $\mathrm{D} / \mathrm{E}$ & 161 & $31.5(24.4-39.7)$ & 1,484 & $30.2(25.8-35.1)$ & \\
\hline Country region & & & & & 0.001 \\
\hline North & 40 & $1.4(0.7-2.7)$ & 1,046 & $5.4(4.2-7.0)$ & \\
\hline Northeast & 105 & $25.6(16.9-36.8)$ & 1,112 & $29.4(22.0-38.1)$ & \\
\hline Midwest & 69 & $3.3(1.6-6.5)$ & 1,031 & $5.8(4.1-8.1)$ & \\
\hline Southeast & 136 & $32.2(20.6-46.6)$ & 1,282 & $33.6(25.8-42.3)$ & \\
\hline South & 253 & $37.5(25.4-51.4)$ & 1,437 & $25.8(19.3-33.6)$ & \\
\hline Private health insurance (yes) & 72 & $12.4(8.1-18.5)$ & 532 & $9.9(7.2-13.4)$ & 0.169 \\
\hline
\end{tabular}

NB: anweighted n-value; ${ }^{b}$ According to Brazilian Law 10,406/2002, the common-law marriage between man and woman is defined as a family entity, configured in the public coexistence, continuous and lasting and established with the purpose of family formation. ${ }^{C}$ According to the Brazilian Criteria 2015 and social class distribution update for 2016, available in <http://www.abep.org/criterio-brasil >.

Regarding self-reported lifestyle and health characteristics, $17.0 \%$ of statins users consumed alcohol more than once a month, $14.4 \%$ were smokers, $30.8 \%$ reported physical activities in the 
three months prior to the interview and $77.4 \%$ reported to adopt a diet with fat reduction (Table 2). Accessing emergency care was reported by $21.8 \%$ and $9.6 \%$ required hospitalization in the year prior to the interview.

Table 2. Lifestyle characteristics and indicators of health conditions of the statins users in SUS primary health care. National Survey on Access, Use and Promotion of Rational Use of Medicines - Services, 2015

\begin{tabular}{|c|c|c|c|c|c|}
\hline \multirow{3}{*}{ Variables } & \multicolumn{4}{|c|}{ Current statin users } & \multirow{3}{*}{ p-value } \\
\hline & \multicolumn{2}{|c|}{ Yes $(n=603)$} & \multicolumn{2}{|c|}{ No $(n=5,908)$} & \\
\hline & $\mathbf{n}^{\mathbf{a}}$ & $\%(95 \% \mathrm{CI})$ & $\mathbf{n}^{\mathbf{a}}$ & $\%(95 \% \mathrm{CI})$ & \\
\hline Alcohol consumption (yes) ${ }^{\mathbf{b}}$ & 9 & $17.0(13.0-22.0)$ & 1,353 & $21.5(19.2-24.0)$ & 0.080 \\
\hline Smoking (yes) & 84 & $14.4(10.8-19.0)$ & 727 & $13.3(11.9-14.9)$ & 0.568 \\
\hline Physical activity (yes) ${ }^{\mathbf{c}}$ & 187 & $30.8(25.1-37.1)$ & 1,583 & $26.0(22.7-29.6)$ & 0.066 \\
\hline Fat reduction diet (yes) & 493 & $77.4(72.8-81.4)$ & 3,504 & $58.4(55.1-61.5)$ & $<0.001$ \\
\hline Self-perception of health & & & & & 0.006 \\
\hline Good/very good & 253 & $40.3(31.6-49.6)$ & 3,178 & $53.0(50.1-55.9)$ & \\
\hline Neither bad/nor good & 279 & $48.1(39.7-56.6)$ & 2,193 & $38.0(35.8-40.2)$ & \\
\hline Bad/very bad & 70 & $11.6(7.8-17.0)$ & 528 & $9.1(7.8-10.5)$ & \\
\hline Number of chronic diseases & & & & & $<0.001$ \\
\hline None & 11 & $2.4(1.0-5.3)$ & 1,583 & $24.8(22.6-27.2)$ & \\
\hline One & 70 & $12.8(9.2-17.6)$ & 1,592 & $28.8(27.1-30.6)$ & \\
\hline Two or more & 492 & $84.9(79.7-88.9)$ & 2,481 & $46.4(43.5-49.3)$ & \\
\hline \multicolumn{6}{|l|}{ Chronic diseases } \\
\hline - Diseases of the circulatory system & 456 & $76.6(71.4-81.1)$ & 2,585 & $47.7(44.7-50.8)$ & $<0.001$ \\
\hline Hypertension & 439 & $73.0(67.8-77.7)$ & 2,500 & $45.9(42.8-79.0)$ & \\
\hline Heart diseases & 153 & $24.1(18.2-31.3)$ & 444 & $8.1(6.8-9.5)$ & \\
\hline Stroke & 35 & $4.7(2.8-7.7)$ & 165 & $2.9(2.3-3.8)$ & \\
\hline - Metabolic diseases & 523 & $87.6(83.4-90.9)$ & 1,679 & $29.2(26.9-31.6)$ & $<0.001$ \\
\hline Dyslipidemia & 481 & $81.4(76.5-85.4)$ & 1,260 & $21.7(19.7-23.8)$ & \\
\hline Diabetes mellitus & 234 & $36.6(32.5-40.9)$ & 843 & $15.1(13.2-17.1)$ & \\
\hline - Others & 374 & $62.0(54.9-68.7)$ & 2,916 & $52.4(49.0-55.7)$ & 0.001 \\
\hline Arthritis, arthrosis, or rheumatism & 222 & $35.8(30.3-41.8)$ & 1,273 & $22.3(19.8-25.0)$ & \\
\hline Depression & 166 & $25.8(20.2-32.3)$ & 1,176 & $21.7(19.1-24.5)$ & \\
\hline Chronic pulmonary disease & 75 & $9.8(6.9-13.6)$ & 657 & $10.7(9.3-12.2)$ & \\
\hline Other diseases & 152 & $26.0(20.7-32.0)$ & 1,227 & $21.5(18.1-25.4)$ & \\
\hline Number of drugs used & & & & & $<0.001$ \\
\hline 1 & 46 & $7.9(5.5-11.1)$ & 2,515 & $40.7(37.6-44.0)$ & \\
\hline $2-4$ & 319 & $55.1(47.5-62.6)$ & 3,021 & $52.6(50.0-55.1)$ & \\
\hline$\geq 5$ (polypharmacy) & 238 & $37.0(28.9-45.9)$ & 372 & $6.7(5.4-8.3)$ & \\
\hline Emergency care (yes) ${ }^{\mathrm{d}}$ & 147 & $21.8(17.4-27.1)$ & 1,643 & $25.2(22.9-27.7)$ & 0.164 \\
\hline Hospitalization (yes) & 67 & $9.6(6.5-13.9)$ & 632 & $10.7(9.1-12.5)$ & 0.542 \\
\hline
\end{tabular}

NB: aUnweighted n-value; bAlcohol use were considered positive for report of more than once per month; "Report of physical activity or sports in the three months preceding the interview; dSelf-report referring to the 12 months prior to the interview

The self-perception of health was neither good/nor bad for $48.1 \%$ and very good/good for $40.3 \%$ of statins users. Most of the statins users reported having two or more chronic diseases $(84.9 \%)$, with dyslipidemia $(81.4 \%)$, hypertension $(73.0 \%)$ and diabetes mellitus $(36.6 \%)$ the most prevalent. The average number of medicines consumed per patient was $4.1 \pm 0.41$, with the 
prevalence of polypharmacy at $37.0 \%$. The most commonly used statin was simvastatin $(90.3 \%)$, followed by atorvastatin $(4.7 \%)$ and rosuvastatin $(1.9 \%)$ (Table 3$)$. Rosuvastatin was the only reported statin that is not included in the National List of Essential Medicines (RENAME).

Table 3. Access, use and adherence to statins in the SUS primary health care services. National Survey on Access, Use and Promotion of Rational Use of Medicines - Services, 2015

\begin{tabular}{|c|c|c|}
\hline Variable & $n^{a}(603)$ & $\%(95 \%$ CI $)$ \\
\hline \multicolumn{3}{|l|}{ Statin (ATC code) ${ }^{b}$} \\
\hline Simvastatin $^{\mathrm{c}}(\mathrm{C} 10 \mathrm{AA} 01)$ & 576 & $90.3(84.2-94.2)$ \\
\hline Atorvastatin (C10AA05) & 21 & $4.7(1.7-12.4)$ \\
\hline Rosuvastatin $^{\mathrm{d}}(\mathrm{C} 10 \mathrm{AA} 07)$ & 11 & $1.9(0.9-3.9)$ \\
\hline Pravastatin (C10AA03) & 1 & $0.2(0.0-1.4)$ \\
\hline \multicolumn{3}{|l|}{ Time using statin } \\
\hline$<1$ year & 115 & $18.6(14.9-22.9)$ \\
\hline$\geq 1$ year & 488 & $81.4(77.1-85.1)$ \\
\hline$<1$ year & 115 & $18.6(14.9-22.9)$ \\
\hline \multicolumn{3}{|l|}{ Access to statin } \\
\hline SUS Pharmacy (free of charge) & 387 & $68.1(59.6-75.5)$ \\
\hline Private Pharmacy & 111 & $16.7(13.5-20.5)$ \\
\hline Popular Pharmacy c (co-payment) & 95 & $13.8(8.2-22.3)$ \\
\hline Other & 10 & $1.5(0.6-4.6)$ \\
\hline Self-reported of poor adherence ${ }^{\mathrm{e}}$ (yes) & 41 & $6.5(3.5-12.0)$ \\
\hline \multicolumn{3}{|l|}{ Causes of non-adherence } \\
\hline Decision not to take the medicine & 8 & $30.7(18.6-46.1)$ \\
\hline Forgotten dose & 9 & $24.1(12.3-41.9)$ \\
\hline Lack of drug access $f$ & 15 & $23.5(13.5-37.5)$ \\
\hline Adverse events & 4 & $10.6(2.9-31.7)$ \\
\hline Other & 5 & $11.2(4.6-24.7)$ \\
\hline
\end{tabular}

NB: aUnweighted $\mathrm{n}$ value; ${ }^{\mathrm{b}}$ According to level five of the Anatomical Therapeutic Chemical (ATC) Classification Index (WHO, 2016); ' Simvastatin is available in Popular Pharmacy Program network. The Ministry of Health fund up to $90 \%$ of the drugs price and the patient pays the difference between the product selling price and the percentage funded by the federal government ${ }^{\mathrm{d} D r u g}$ not provided by SUS; ePatients reported didn't take almost one statin dose up to 7 days before the interview; fPatients didn't have prescription or the statin wasn't available in SUS Pharmacies.

Most statin users (81.4\%) reported using statins for at least one year, and $71.0 \%$ received information on how to use their medicines during the last dispensing.

Losartan was the most co-prescribed medicine with statins $(33.2 \%, n=200)$, followed by metformin $(22.9 \% n=138)$, omeprazole $(16.9 \% n=102)$, hydrochlorothiazide $(14.6 \% n=88)$ and enalapril $(14.4 \% \mathrm{n}=87)$. When patients were asked about their statin supply, $68.1 \%$ reported getting their medicines free of charge; whereas $13.8 \%$ reported obtaining them from the Popular Pharmacy Program (10\% co-payment).

Poor adherence, defined as missing at least one dose of statin in the seven days prior to the interview, was described by $6.5 \%$ of patients. Deciding not to take the statin was indicated as the main reason of non-adherence $(30.7 \%)$, followed by forgetting doses $(24.1 \%)$, the lack of access resulting from SUS unavailability (23.5\%) and occurrence of adverse events (10.6\%).

The results of the multiple logistic regression model for the predictors of statin use are presented in Table 4. The use of statins was significantly associated with age, with elderly people almost three times more likely to take a statin (OR 2.94, 95\% Cl 1.72-5.04). Patients 
with higher education had approximately double the chance of taking statins versus those who were illiterate/incomplete elementary school (OR $2.2495 \% \mathrm{Cl} 1.25-4.02)$. Residents of the South (OR $3.5595 \% \mathrm{Cl} 1.84-6.84$ ), Northeast (OR $2.7695 \% \mathrm{Cl} 1.41-5.39$ ) and Southeast regions (OR $2.5395 \% \mathrm{Cl}$ 1.26-5.08) had greater statin utilisation than those in the North and Midwest regions. People with metabolic disorders, characterized by dyslipidemia and diabetes mellitus, had a 9.78-fold higher chance of taking a statin, and patients with heart disease were 1.57 times more likely to be taking a statin. Statins use was associated with the number of medicines being taken, and the greatest strength association was with polypharmacy (OR 10.08 $95 \% \mathrm{Cl} 6.45-15.75)$. Alcohol consumption above once per month, and not having attended emergency services, were also associated with statin use (OR $1.41[95 \% \mathrm{Cl} 1.01-1.99 \%]$ and OR 1.87 [95\% Cl $1.29-2.70 \%]$, respectively). There was no statistically significant difference in adherence to statins according to the access: $68.0 \%$ (CI95\% 59.3-75.6) of adherent patients accessed statins free of charge in SUS pharmacies and 69.8\% (CI95\% 46.6-86.0) accessed statin in private pharmacies $(p$-value $=0.864)$.

Table 4. Associated factors (odds ratio) to statins use in SUS primary health care services patients according to the multiple logistic regression model. National Survey on Access, Use and Promotion of Rational Use of Medicines - Services, 2015

\begin{tabular}{|c|c|c|c|}
\hline Variables & OR & CI 95\% OR & p-value \\
\hline Age (years) & & & $<0.001$ \\
\hline $18-44$ & - & - & \\
\hline $45-64$ & 2.821 & $(1.614 ; 4.931)$ & \\
\hline$\geq 65$ & 2.943 & $(1.718 ; 5.042)$ & \\
\hline Education level & & & $0.234^{\mathrm{a}}$ \\
\hline Illiterate/ Incomplete elementary school & - & - & \\
\hline Elementary school & 1.370 & $(0.974 ; 1.927)$ & \\
\hline High school ${ }^{\mathrm{a}}$ & 1.475 & $(1.022 ; 2.127)$ & \\
\hline Higher education $^{\text {a }}$ & 2.237 & $(1.246 ; 4.015)$ & \\
\hline Region of residence & & & 0.003 \\
\hline North & - & - & \\
\hline Midwest & 2.227 & $(1.073 ; 4.621)$ & \\
\hline Southeast & 2.533 & $(1.263 ; 5.078)$ & \\
\hline Northeast & 2.760 & $(1.414 ; 5.386)$ & \\
\hline South & 3.550 & $(1.843 ; 6.837)$ & \\
\hline Metabolic diseases ${ }^{b}$ & & & $<0.001$ \\
\hline No & - & - & \\
\hline Yes & 9.778 & $(6.554 ; 14.587)$ & \\
\hline Heart diseases & & & $<0.001$ \\
\hline No & - & - & \\
\hline Yes & 1.570 & $(1.112 ; 2.218)$ & \\
\hline Number of drugs used & & & $<0.001$ \\
\hline 1 & - & - & \\
\hline $2-4$ & 2.805 & $(1.844 ; 4.268)$ & \\
\hline$\geq 5$ (polypharmacy) & 10.077 & $(6.451 ; 15.739)$ & \\
\hline Alcohol use & & & 0.005 \\
\hline No & - & - & \\
\hline Yes & 1.414 & $(1.010 ; 1.982)$ & \\
\hline Emergency care & & & $<0.001$ \\
\hline No & 1.866 & $(1.291 ; 2.697)$ & \\
\hline Yes & - & - & \\
\hline
\end{tabular}

\section{Discussion}

The prevalence of statin use in Brazilian primary health care in this study $(9.3 \%)$ was lower than in high income countries, such as the United Kingdom (12.8\% of patients) [51], and the United States (17.2\% of patients) [52]; however. higher than seen in low middle income countries (4.9\%), including China and Colombia [53-55]. This prevalence rate may be explained by a 
recent longitudinal study of adults' health in Brazil (ELSA-Brazil cohort) [56] demonstrating that, according to the National guideline for CVD prevention, only a small fraction of eligible statins users are actually taking them. In addition, SUS has never developed clear guidelines for the use of statins in primary prevention [56], which may also go some way to explaining lower prevalence rates in Brazil. However, primary prevention with statins is controversial in view of the large number of patients needed to treat to prevent one cardiac event [57].

Current guidelines for CVD prevention and treatment emphasize non-pharmacological approaches including physical activity and cessation of smoking $[6,19,21,22]$. In this study among statins users, $14.4 \%$ were smokers and just $30 \%$ self-reported physical activities in the three months preceding the interview, without a significant statistical difference between statin users and non users of statins. The adoption of a fat reduction diet was higher $(77.4 \%)$, but this also represents a challenge.

Not surprisingly statin use was associated with metabolic and heart diseases as diabetes itself is an independent risk factor for CVD [27, 58,59]. Even though concerns have been raised about the potential diabetogenic effect of statin therapy, statins significantly reduce the risk for atherosclerotic cardiovascular disease in patients with diabetes and continue to be recommended $[17,30,60]$.

Statin use was also associated with higher schooling levels and the Brazilian region of residence, with the greatest association found in the South region. This needs to be addressed with the prevalence of NCDs, such as hypertension, diabetes, and stroke higher in patients with low schooling levels (illiterate and incomplete elementary school), and the negative impact of NCDs on quality of life is greater in the lower educational level population [15,61]. The associated factors with statins use found in this study reinforce previous studies [15,61], indicating that inequalities in health care persist in Brazil, with people with high risk to CVD not using statins. As mentioned, this needs to be urgently addressed to reduce the morbidity and mortality associated with CVD.

The use of statins was also associated with age, and elderly people were almost three times more likely to use them. Albeit elderly people face the greatest risk and burden of CVD mortality and morbidity [62], the current lack of evidence substantially challenges efforts to reach optimal health decisions for the aging population, especially for CVD primary prevention [63]. Establishing shared decision making is crucial, balancing the benefits and the potential risks of statins use for CVD prevention involving older patients [62,63], especially given the level of polypharmacy found in this study. Polypharmacy is increasingly common in clinical practice, and it has been linked to negative health outcomes, increased morbidity and mortality, reduction of the quality of life, and increased costs of care, with concerns to patients and healthcare systems $[43,64]$. Consequently, statin users need to be regularly monitored for any occurrence of drug interactions in addition to issues of adherence, and health care teams need to undertake regular medication reviews in order to identify non-essential medicines and their potential deprescription, customizing the treatment in people with multimorbidity and more complex diseases, or specific vulnerability $[64,65]$, to optimise their use and other essential medicines.

Simvastatin was the most used statin in primary health care patients, followed by atorvastatin and rosuvastatin. This was expected as simvastatin is the recommended statin in primary health care. The low use of the other statins could be related to the pre-assessment process [22], which can cause a delay between prescription and authorization (or not) for dispensing the medicines. In addition, rosuvastatin is current subject to $100 \%$ co-payment. These findings are similar to other studies where prescribing restrictions have significantly affected statin use [29,66-68]. However, other studies focusing on the implementation of national guidelines for CVD prevention are needed to better understand these results.

Although the self-reported adherence to statin therapy in this study was higher than the average seen in other studies [69-71], this could be overestimated. As a result, statin adherence and persistence in Brazil needs to be better understood, especially in patients on multiple medications and where there could be concerns with affordability. This is because public supply is the only way to access medicines among low income families in Brazil [72,73] as just $24.5 \%$ of Brazilian population currently have private health insurance [74]. The lack of free-of-charge 
statin in patients may compromise family budgets and subsequent treatment persistence. However, the updating of the Popular Pharmacy Program, including statins in the "Saúde não tem preço" ("Health is priceless") strategy, may contribute to increased adherence to treatment, and strengthen the prevention and control of CVD policy in Brazil. These will be subjects of future research since one of the key challenges in CVD prevention is to improve adherence and persistence to drug treatment $[19,33]$.

Lack of access, forgotten doses and adverse effects accounted for more than half of the reasons for non-adherence in SUS primary health care patients. This is in line with other studies $[4,52,70,71]$ in which unintentional non adherence was dominant. The lack of access could be related to the poor availability of essential medicines in Brazilian primary health care. However, currently limited or no co-payment for designated statins in this study reinforce the availability of essential medicines in SUS primary health care services previously reported [75,76], highlighting that ensuring access to essential medicines is still a challenge to the Brazilian health system. According to the WHO [8], an $80 \%$ availability of the affordable basic technologies and essential medicines, including generics, is required to treat major NCDs in both public and private facilities, which is a global target for prevention and control of these diseases. Consequently, to achieve WHO goals it is necessary to better understand the lack of statin access where this occurs in Brazil even when these medicines are provided at no or limited costs.

This study has important strengths, but some limitations as well. The main advantage is the nationally representative sample of the population with data from health surveys constituting an acceptable approach to estimate health needs and the prevalence of specific problems in a national population $[38,74]$. However, it was not possible to establish the temporality of the associated factors and the causality relation. In addition, the results were based on self-reported data which may be subject to recall bias. Furthermore, it wasn't possible to evaluate primary non-adherence because questions about adherence were addressed just to medicine users. Despite these concerns, we believe the findings are robust, providing guidance for future strategies in Brazil to reduce the morbidity and mortality associated with NCDs.

\section{Conclusions}

In Brazil, statin use was associated with age, educational level, region of residence, polypharmacy and alcohol consumption. Non-pharmacological approaches are still challenging and policies encouraging a healthy lifestyle, in addition to investments in primary health care, need to be strengthened to address inequalities in access and use of medicines where these exist to improve statin use. However, the average number of medicines used per person, and the association between polypharmacy and statins use, may be a concern if related to the inappropriate use of medicines. High adherence rates to statins is encouraging, but this could be overestimated. These factors need further evaluation as the rational use of medicines, as well as improving adherence to statins, are key areas to help reduce cardiovascular events in patients with CVD.

Overall, this study presents baseline information on statin use across Brazil and could contribute to developing future programs including the planning and management of health interventions aimed at reducing morbidity, mortality and costs due to CVD. Universal and sustainable financing, reliable supply systems, strengthening public health systems and high adherence to medicines are required to achieve a meaningful reduction in CVD morbidity and mortality. Eliminating simvastatin out-of-pocket costs where this exists, improving compliance with statin use recommendations, and addressing remaining disparities, will be important steps in Brazil to realise the full benefits of statin use. These are important considerations for the future.

Authors' Contributions: RCRMN - concept and design, data analysis and interpretation, and the manuscript draft. ICG - data analysis, interpretation and manuscript draft. JA, FAA, and AAG Jr. - concept and design, data review and interpretation, and manuscript draft review. BG, $M B$ and $A B K$ critical involvement and review of the manuscript, discussion of successive drafts. All authors approved the final version and agreed to be accountable for all aspects of the work. 


\section{Declaration of funding}

This study was funded by the Department for Pharmaceutical Services and Strategic Health Supplies and the Department of Science and Technology of the Secretariat of Science, Technology and Strategic Supplies of the Brazilian Ministry of Health (SCTIE/MS - Process 25000.111834/2, Decentralization of FNS Resources).

Declaration of financial/other relationships

The authors declare they have no other conflicts of interest.

Acknowledgements: There was no assistance in the preparation of this paper.

\section{References}

1. World Health Organization (WHO). Global Status Report on Noncommunicable Diseases 2014 [Internet]. WHO; 31 Mar 2015. Available:

https://books.google.com/books/about/Global_Status_Report_on_Noncommunicable.html?hl=\&i $\mathrm{d}=$ INoOrgEACAAJ

2. World Health Organization (WHO). Global action plan for the prevention and control of noncommunicable diseases 2013-2020. In: http://who.int/en/ [Internet]. 2013 [cited 29 Sep 2017]. Available: http://apps.who.int/iris/bitstream/10665/94384/1/9789241506236_eng.pdf

3. Beaglehole R, Epping-Jordan J, Patel V, Chopra M, Ebrahim S, Kidd M, et al. Improving the prevention and management of chronic disease in low-income and middle-income countries: a priority for primary health care. Lancet. 2008;372: 940-949.

4. Roth GA, Forouzanfar MH, Moran AE, Barber R, Nguyen G, Feigin VL, et al. Demographic and epidemiologic drivers of global cardiovascular mortality. N Engl J Med. 2015;372: 1333-1341.

5. World Health Organization (WHO). Global Status Report on Noncommunicable Diseases 2014 [Internet]. WHO; 31 Mar 2015. Available:

https://books.google.com/books/about/Global_Status_Report_on_Noncommunicable.html?hl=\&i $\mathrm{d}=$ INoOrgEACAAJ

6. Pan American Health Organization (PAHO). Plan of action for the prevention and control of noncommunicable diseases. In: http://www.paho.org/hq/ [Internet]. PAHO; 2014 [cited 17 Sep 2029]. Available: file:///C:/Users/fdb17123/Downloads/action-plan-prevention-control-ncdsamericas.pdf

7. Nashilongo MM, Singu B, Kalemeera F, Mubita M, Naikaku E, Baker A, et al. Assessing Adherence to Antihypertensive Therapy in Primary Health Care in Namibia: Findings and Implications. Cardiovasc Drugs Ther. 2017; doi:10.1007/s10557-017-6756-8

8. World Health Organization (WHO). Global action plan for the prevention and control of noncommunicable diseases 2013-2020. In: http://who.int/en/ [Internet]. 2013 [cited 29 Sep 2017]. Available: http://apps.who.int/iris/bitstream/10665/94384/1/9789241506236_eng.pdf

9. Wirtz VJ, Hogerzeil HV, Gray AL, Lancet Commission on Essential Medicines Policies. Essential medicines for universal health coverage - Authors' reply. Lancet. 2017;389: 18811882.

10. Simoens S, Sinnaeve PR. Patient co-payment and adherence to statins: a review and case studies. Cardiovasc Drugs Ther. 2014;28: 99-109.

11. Sinnott SJ, Buckley C, O'Riordan D, Bradley C, Whelton H. The Effect Of Copayments For Prescriptions On Adherence To Medicines In Publicly Insured Populations: A Systematic Review And Meta-Analysis. Value Health. 2013;16: A207.

12. Choudhry NK, Avorn J, Glynn RJ, Antman EM, Schneeweiss S, Toscano M, et al. Full coverage for preventive medications after myocardial infarction. N Engl J Med. 2011;365: 2088-2097. 
13. Caires de Souza AL, de Souza ALC, de Assis Acurcio F, Júnior AAG, do Nascimento RCRM, Godman B, et al. Insulin Glargine in a Brazilian State: Should the Government Disinvest? An Assessment Based on a Systematic Review. Appl Health Econ Health Policy. 2014;12: 19-32.

14. Mansur A de P, de Padua Mansur A, Favarato D. Mortality due to Cardiovascular Diseases in Women and Men in the Five Brazilian Regions, 1980-2012. Arq Bras Cardiol. 2016; doi:10.5935/abc.20160102

15. Malta DC, Bernal RTI, de Souza M de FM, Szwarcwald CL, Lima MG, de Azevedo Barros MB. Social inequalities in the prevalence of self-reported chronic non-communicable diseases in Brazil: national health survey 2013. Int J Equity Health. 2016;15. doi:10.1186/s12939-016-04274

16. Baena CP, Chowdhury R, Schio NA, Sabbag AE Jr, Guarita-Souza LC, Olandoski M, et al. Ischaemic heart disease deaths in Brazil: current trends, regional disparities and future projections. Heart. 2013;99: 1359-1364.

17. Heart Protection Study Collaborative Group. MRC/BHF Heart Protection Study of cholesterol lowering with simvastatin in 20,536 high-risk individuals: a randomised placebo-controlled trial. Lancet. 2002;360: 7-22.

18. Choudhry NK. Improving the pathway from cardiovascular medication prescribing to longer-term adherence: new results about old issues. Circ Cardiovasc Qual Outcomes. 2010;3: 223-225.

19. Rabar S, Harker M, O'Flynn N, Wierzbicki AS, On behalf of the Guideline Development Group. Lipid modification and cardiovascular risk assessment for the primary and secondary prevention of cardiovascular disease: summary of updated NICE guidance. BMJ. 2014;349: g4356-g4356.

20. Cholesterol Treatment Trialists' (CTT) Collaboration, Fulcher J, O'Connell R, Voysey M, Emberson J, Blackwell L, et al. Efficacy and safety of LDL-lowering therapy among men and women: meta-analysis of individual data from 174,000 participants in 27 randomised trials. Lancet. 2015;385: 1397-1405.

21. Faludi AA, Izar M, Saraiva J, Chacra A, Bianco HT, Afiune Neto A, et al. ATUALIZAÇÃO DA DIRETRIZ BRASILEIRA DE DISLIPIDEMIAS E PREVENÇÃO DA ATEROSCLEROSE - 2017. Arq Bras Cardiol. 2017;109. doi:10.5935/abc.20170121

22. da Saude BM. Portaria SMS no 200, de 25 de fevereiro 2013. Aprova o Protocolo Clínico e Diretrizes Terapêuticas da Dislipidemia para a prevenção de eventos cardiovasculares e pancreatite. In: http://bvsms.saude.gov.br/bvs/saudelegis [Internet]. Brasil. Ministerio da Saude; 25 Feb 2013 [cited 28 Aug 2017]. Available: http://bvsms.saude.gov.br/bvs/saudelegis/sas/2013/prt0200_25_02_2013.html

23. Nédó E, Paulik E. Association of smoking, physical activity, and dietary habits with socioeconomic variables: a cross-sectional study in adults on both sides of the HungarianRomanian border. BMC Public Health. BioMed Central; 2012;12: 60.

24. Pampel FC, Krueger PM, Denney JT. Socioeconomic Disparities in Health Behaviors. Annu Rev Sociol. NIH Public Access; 2010;36: 349.

25. Weng T-C, Yang Y-HK, Lin S-J, Tai S-H. A systematic review and meta-analysis on the therapeutic equivalence of statins. J Clin Pharm Ther. 2010;35: 139-151.

26. DiNicolantonio JJ, Lavie CJ, Serebruany VL, O'Keefe JH. Statin Wars: The Heavyweight MatchAtorvastatin versus Rosuvastatin for the Treatment of Atherosclerosis, Heart Failure, and Chronic Kidney Disease. Postgrad Med. 2013;125: 7-16.

27. Godman B, Shrank W, Andersen M, Berg C, Bishop I, Burkhardt T, et al. Comparing policies to enhance prescribing efficiency in Europe through increasing generic utilization: changes seen and global implications. Expert Rev Pharmacoecon Outcomes Res. 2010;10: 707-722. 
28. Godman B, Burkhardt T, Bucsics A, Wettermark B, Wieninger P. Impact of recent reforms in Austria on utilization and expenditure of PPIs and lipid-lowering drugs: implications for the future. Expert Rev Pharmacoecon Outcomes Res. 2009;9: 475-484.

29. Sakshaug S, Furu K, Karlstad Ø, Rønning M, Skurtveit S. Switching statins in Norway after new reimbursement policy: a nationwide prescription study. Br J Clin Pharmacol. 2007;64: 476-481.

30. Bennie M, Godman B, Bishop I, Campbell S. Multiple initiatives continue to enhance the prescribing efficiency for the proton pump inhibitors and statins in Scotland. Expert Rev Pharmacoecon Outcomes Res. 2012;12: 125-130.

31. Yamauti SM, Barberato-Filho S, Lopes LC. Elenco de medicamentos do Programa Farmácia Popular do Brasil e a Política de Nacional Assistência Farmacêutica. Cadernos de Saúde Pública. 2015;31: 1648-1662.

32. Ribeiro RA, Duncan BB, Ziegelmann PK, Stella SF, da Costa Vieira JL, Restelatto LMF, et al. Cost-Effectiveness of High, Moderate and Low-Dose Statins in the Prevention of Vascular Events in the Brazilian Public Health System. Arq Bras Cardiol. 2014; doi:10.5935/abc.20140173

33. Cramer JA, Benedict A, Muszbek N, Keskinaslan A, Khan ZM. The significance of compliance and persistence in the treatment of diabetes, hypertension and dyslipidaemia: a review. Int $\mathrm{J}$ Clin Pract. 2008;62: 76-87.

34. Colantonio LD, Huang L, Monda KL, Bittner V, Serban MC, Taylor B, et al. Adherence to HighIntensity Statins Following a Myocardial Infarction Hospitalization Among Medicare Beneficiaries. JAMA cardiology. 2017;2(8):890-5

35. Herttua K, Martikainen P, Batty GD, Kivimäki M. Poor Adherence to Statin and Antihypertensive Therapies as Risk Factors for Fatal Stroke. Journal of the American College of Cardiology. 2016;67(13):1507-15

36. Gomez J. InterMountain Healthcare. Heart Attack and Stroke Patients Prescribed Statin Medication Upon Discharge Have Better Long-Term Outcomes. 2017. Available at URL: https://intermountainhealthcare.org/news/2017/10/heart-attack-stroke-patients-prescribed-statinmedication-have-better-outcomes/

37. Bitton A, Choudhry NK, Matlin OS, Swanton K, Shrank WH. The impact of medication adherence on coronary artery disease costs and outcomes: a systematic review. The American journal of medicine. 2013;126(4):357 e7- e27 + 20,21

38. Malta DC, Szwarcwald CL. Population-based surveys and monitoring of noncommunicable diseases. Revista de Saúde Pública. 2017;51. doi:10.1590/s1518-8787.201705100supl1ap

39. Álvares J, Maria Cecilia Goi, Loureiro MM, Almeida AM, Izidoro JB, Guerra AA, et al. National Survey on Access, Use and Promotion of Rational Use of Medicines: methods. Rev Saude Publica. 2017;51: 4s.

40. Schmidt MI, Duncan BB, Azevedo e Silva G, Menezes AM, Monteiro CA, Barreto SM, et al. Chronic non-communicable diseases in Brazil: burden and current challenges. Lancet. 2011;377: 1949-1961.

41. ABEP- Brazilian Market Research Association. Brazilian Criteria 2015 and social class distribution update for 2016. In: ABEP - Associação Brasileira de Empresas de Pesquisa [Internet]. 2016 [cited 28 Aug 2017]. Available: file:///C:/Users/fdb17123/Downloads/01_cceb_2016_11-04-16_Eng-US\%20(2).pdf

42. WHO Collaborating Centre for Drug Statistics Methodology. Anatomical Therapeutic Chemical (ATC) Classification Index 2016. In: WHO [Internet]. 2016 [cited 5 Oct 2017]. Available: http://www.whocc.no/atc_ddd_index/ 
43. Patterson SM, Cadogan CA, Kerse N, Cardwell CR, Bradley MC, Ryan C, et al. Interventions to improve the appropriate use of polypharmacy for older people. The Cochrane database of systematic reviews. 2014(10):Cd008165

44. Guthrie B, Makubate B, Hernandez-Santiago V, Dreischulte T. The rising tide of polypharmacy and drug-drug interactions: population database analysis 1995-2010. BMC Med. 2015;13: 74.

45. Marković-Peković V, Škrbić R, Petrović A, Vlahović-Palčevski V, Mrak J, Bennie M, et al. Polypharmacy among the elderly in the Republic of Srpska: extent and implications for the future. Expert Rev Pharmacoecon Outcomes Res. 2016;16: 609-618.

46. Nascimento RCRM, Álvares J, Guerra AA, Gomes IC, Silveira MR, Costa EA, et al. Polypharmacy: a challenge for the primary health care of the Brazilian Unified Health System. Rev Saúde Pública. 2017;51: 19s.

47. Lehmann A, Aslani P, Ahmed R, Celio J, Gauchet A, Bedouch P, et al. Assessing medication adherence: options to consider. Int J Clin Pharm. 2014;36: 55-69.

48. Garfield S, Clifford S, Eliasson L, Barber N, Willson A. Suitability of measures of self-reported medication adherence for routine clinical use: a systematic review. BMC Med Res Methodol. 2011;11: 149.

49. Schedlbauer A, Davies P, Fahey T. Interventions to improve adherence to lipid lowering medication. Cochrane Database of Systematic Reviews. 2010.

50. Montgomery DC. Introduction to Linear Regression Analysis, Fifth Edition Set. Wiley; 2013.

51. O'Keeffe AG, Nazareth I, Petersen I. Time trends in the prescription of statins for the primary prevention of cardiovascular disease in the United Kingdom: a cohort study using The Health Improvement Network primary care data. Clin Epidemiol. 2016;8: 123-132.

52. Adedinsewo D, Taka N, Agasthi P, Sachdeva R, Rust G, Onwuanyi A. Prevalence and Factors Associated With Statin Use Among a Nationally Representative Sample of US Adults: National Health and Nutrition Examination Survey, 2011-2012. Clin Cardiol. 2016;39: 491-496.

53. Yusuf S, Islam S, Chow CK, Rangarajan S, Dagenais G, Diaz R, et al. Use of secondary prevention drugs for cardiovascular disease in the community in high-income, middle-income, and low-income countries (the PURE Study): a prospective epidemiological survey. Lancet. 2011;378: 1231-1243.

54. Farzadfar F, Finucane MM, Danaei G, Pelizzari PM, Cowan MJ, Paciorek CJ, et al. National, regional, and global trends in serum total cholesterol since 1980: systematic analysis of health examination surveys and epidemiological studies with 321 country-years and 3.0 million participants. Lancet. 2011;377: 578-586.

55. Tolonen H, Keil U, Ferrario M, Evans A, WHO MONICA Project. Prevalence, awareness and treatment of hypercholesterolaemia in 32 populations: results from the WHO MONICA Project. Int J Epidemiol. 2005;34: 181-192.

56. Bittencourt MS, Staniak HL, Pereira AC, Santos IS, Duncan BB, Santos RD, et al. Implications of the New US Cholesterol Guidelines in the Brazilian Longitudinal Study of Adult Health (ELSABrasil). Clin Cardiol. 2016;39: 215-222.

57. Taylor F, Huffman MD, Macedo AF, Moore THM, Burke M, Smith GD, et al. Statins for the primary prevention of cardiovascular disease. Cochrane Database of Systematic Reviews. 2013.

58. Pavanello C, Mombelli G. Considering gender in prescribing statins: what do physicians need to know? Clin Lipidol. 2015;10: 499-512. 
59. Sattar N. Revisiting the links between glycaemia, diabetes and cardiovascular disease. Diabetologia. 2013;56: 686-695.

60. Mortensen MB, Kulenovic I, Falk E. Statin use and cardiovascular risk factors in diabetic patients developing a first myocardial infarction. Cardiovasc Diabetol. BioMed Central; 2016;15: 81.

61. Guimarães RM, Andrade SSC de A, Machado EL, Bahia CA, Oliveira MM de, Jacques FVL. [Regional differences in cardiovascular mortality transition in Brazil, 1980 to 2012]. Rev Panam Salud Publica. 2015;37: 83-89.

62. Pedro-Botet J, Climent E, Chillarón JJ, Toro R, Benaiges D, Flores-Le Roux JA. Statins for primary cardiovascular prevention in the elderly. J Geriatr Cardiol. 2015;12: 431-438.

63. Gurwitz JH, Go AS, Fortmann SP. Statins for Primary Prevention in Older Adults. JAMA. 2016;316: 1971.

64. Cadogan CA, Ryan C, Hughes CM. Appropriate Polypharmacy and Medicine Safety: When Many is not Too Many. Drug Saf. 2016;39: 109-116.

65. Secoli S, Danzi N, Lima F, Filho G, Cesar L. Drug interactions in patients with coronary artery disease. Rev Bras Cardiol. International Journal of Cardiovascular Sciences; 2011;25: 11-18.

66. Garuoliene K, Godman B, Gulbinovic J, Schiffers K, Wettermark B. Differences in utilization rates between commercial and administrative databases: implications for future health-economic and cross-national studies. Expert review of pharmacoeconomics \& outcomes research. 2016;16(2):149-52

67. Godman B, Sakshaug S, Berg C, Wettermark B, Haycox A. Combination of prescribing restrictions and policies to engineer low prices to reduce reimbursement costs. Expert review of pharmacoeconomics \& outcomes research. 2011;11(1):121-9.

68. Godman B, Wettermark B, van Woerkom M, Fraeyman J, Alvarez-Madrazo S, Berg C, et al. Multiple policies to enhance prescribing efficiency for established medicines in Europe with a particular focus on demand-side measures: findings and future implications. Front Pharmacol. 2014;5: 106.

69. Deshpande S, Quek RGW, Forbes CA, de Kock S, Kleijnen J, Gandra SR, et al. A systematic review to assess adherence and persistence with statins. Curr Med Res Opin. 2017;33: 769778.

70. Wei MY, Ito MK, Cohen JD, Brinton EA, Jacobson TA. Predictors of statin adherence, switching, and discontinuation in the USAGE survey: understanding the use of statins in America and gaps in patient education. J Clin Lipidol. 2013;7: 472-483.

71. Silvennoinen R, Turunen JH, Kovanen PT, Syvänne M, Tikkanen MJ. Attitudes and actions: A survey to assess statin use among Finnish patients with increased risk for cardiovascular events. J Clin Lipidol. 2017;11: 485-494.

72. Barreto MNS de C, de Carvalho Barreto MNS, Cesse EÂP, Lima RF, da Silva Marinho MG, da Silva Specht $Y$, et al. Analysis of access to hypertensive and diabetic drugs in the Family Health Strategy, State of Pernambuco, Brazil. Rev Bras Epidemiol. 2015;18: 413-424.

73. Helfer AP, Camargo AL, Tavares NUL, Kanavos P, Bertoldi AD. Capacidade aquisitiva e disponibilidade de medicamentos para doenças crônicas no setor público. Rev Panam Salud Publica. 2012;31: 225-232.

74. Viacava F, Bellido JG. Condições de saúde, acesso a serviços e fontes de pagamento, segundo inquéritos domiciliares. Cien Saude Colet. 2016;21: 351-370. 
75. Mendes LV, Campos MR, Chaves GC, da Silva RM, da Silva Freitas P, Costa KS, et al. Disponibilidade de medicamentos nas unidades básicas de saúde e fatores relacionados: uma abordagem transversal. Saúde em Debate. 2014;38. doi:10.5935/0103-1104.2014s009

76. Nascimento RCRM, Álvares J, Guerra AA, Gomes IC, Costa EA, Leite SN, et al. Availability of essential medicines in primary health care of the Brazilian Unified Health System. Rev Saúde Pública. 2017;51: 10s. 